\title{
Björn Pecina
}

\section{Mendelssohns diskrete Religion}

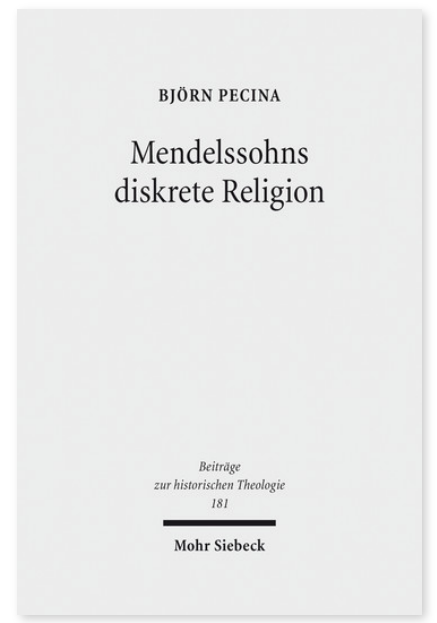

2016. XII, 394 Seiten. BHTh 181

ISBN 978-3-16-153353-2

DOI 10.1628/978-3-16-153353-2

eBook PDF 114,00€

ISBN 978-3-16-153352-5

Leinen $114,00 €$
Es gehört zu den faszinierenden Merkmalen des Aufklärungsjahrhunderts, daß sich hier Rationalisierungs- und Selbstreflexionsprozesse über konfessionelle Grenzen hinwegzusetzen vermochten. Dies führte nicht selten zu einer Öffnung des Religionsbegriffs, der sich als ungemein integrationsfähig erwies. Björn Pecina entfaltet in der vorliegenden Untersuchung ein solches Religionsverständnis, indem er sich dem Werk besonders zweier herausragender Gelehrter zuwendet: Moses Mendelssohn und Johann Friedrich Wilhelm Jerusalem. Jerusalem ist repräsentativ für das Aufklärungsjahrhundert. Er eignet sich gut, die Epoche nach ihrem religionstheoretischen Profil darzustellen, zugleich aber auch Kontinuitäten sichtbar werden zu lassen. Mendelssohn, auf den die Studie ihr Hauptaugenmerk richtet, gelingt es, aparte Religion und aufgeklärte Religionsphilosophie in eine Balance zu bringen.

Björn Pecina Geboren 1967; Studium der Ev. Theologie und der Philosophie; Staatsexamen in Ev. Theologie; 2002/03 Promotion; Kirchliches Vikariat in der Evangelischen Landeskirche Berlin-Brandenburg und 2. Theolog. Examen; 2013 Habilitation; derzeit Privatdozent an der Martin-Luther-Universität Halle-Wittenberg.

\section{Jetzt bestellen:}

https://mohrsiebeck.com/buch/mendelssohns-diskrete-religion-9783161533532?no_cache=1 order@mohrsiebeck.com

Telefon: +49 (0)7071-923-17

Telefax: $+49(0) 7071-51104$ 